\title{
Self-medication during COVID-19 outbreak: a cross sectional online survey in Dhaka city
}

\author{
Morshed Nasir*, A. S. M. Salauddin Chowdhury, Tahmina Zahan
}

Department of Pharmacology and Therapeutics, Holy Family Red Crescent Medical College, Dhaka, Bangladesh

\author{
Received: 16 July 2020 \\ Revised: 02 August 2020 \\ Accepted: 03 August 2020 \\ *Correspondence: \\ Dr. Morshed Nasir, \\ Email: morshednasir@hotmail.com
}

Copyright: (C) the author(s), publisher and licensee Medip Academy. This is an open-access article distributed under the terms of the Creative Commons Attribution Non-Commercial License, which permits unrestricted non-commercial use, distribution, and reproduction in any medium, provided the original work is properly cited.

\begin{abstract}
Background: Self-medication is a common practice in Bangladesh as it provides a low-cost alternative for people, which involves inappropriate and injudicious use of medicines treat self-recognized symptoms by the people.

Methods: A cross sectional online survey was conducted on 626 citizens by structured questionnaires during COVID-19 outbreak from April to May 2020 in Dhaka city, to observe the prevalence, pattern and sources of selfmedication among the respondents with high socio-economic standings and education.

Results: The prevalence of self-medication amid the outbreak of COVID-19 was $88.33 \%$ and only 179 (28.59\%) took medication with doctors' advice and remaining $447(71.40 \%)$ respondents took the drugs as "self-medication" by other sources. The most frequently used prescription-only drug during the outbreak were ivermectin $(77.15 \%)$, azithromycin (54.15\%), doxycycline (40.25\%). The common symptoms for which the respondent took selfmedications were fever, throat pain, dry-cough and total $105(16.77 \%)$ respondents took medications without having any symptoms. Almost $355(85.33 \%)$ had taken medication without doing any test for COVID-19. This could be due to unusual distress, caused by high self-awareness of their health and buying capacity of medication.

Conclusions: The study revealed the causes of self-medication as news of spread, effects and remedies in media channels, internet; mental stress of lockdown and isolation, insecurity and panic about scarcity of drug and healthcare support. High risks of developing antibiotic resistance, adverse drug reactions and financial loss was predictable with absence of strict regulatory enforcement to protect people and proper utilization resources during COVID-19 outbreak in Dhaka city.
\end{abstract}

Keywords: COVID-19, Self-medication, Drug dispensing, Rational use of drug

\section{INTRODUCTION}

The practice of self-medication is prevalent in most parts of Bangladesh regardless of socio-economic status and level of education. While this is indisputable, the incidence of self- medication is may be higher in the low or middle-income countries without consulting with qualified health professionals. ${ }^{1}$ Although the WHO stressed that rational self-medication practice helps in the prevention and treatment of some minor pathological conditions at affordable cost, but otherwise it may cause wastage of resources, resistance to pathogens and serious health hazards with adverse drug reactions and prolonged morbidity. ${ }^{2,3}$ In a developing country like Bangladesh, the practice of self-medication may provide an alternative for people as low-cost to avoid high cost of clinical services and many drugs dispensed over the counter (OTC) without prescription. ${ }^{4}$ But it is gone beyond the OTC drugs and sometimes prescription-only drugs like antimicrobials, sedatives, hypnotics and strong NSAIDs also reported to be dispensed without prescription in few cases. 
According to the World Health Organization (WHO), self-medication is explained as "the selection and use of medicines by individuals (or a member of the individual's family) to treat self-recognized or self-diagnosed conditions or symptoms. Reasons commonly adducted for indulgence in self-medication includes delayed access to healthcare centers, socio cultural belief, relatively high cost of hospital treatment, previous experience of treatment of same symptoms, easy availability of drugs, poor regulatory practice, urgency of feeling relieved, advice from friends and media. Moreover, the ratio between doctor and patient in Bangladesh is currently as low that places the country at second position from the bottom, among the South Asian countries, according to the WHO. ${ }^{5}$ Besides, some individuals practice out of ignorance, poverty and generalized hypes.

Dhaka, being the capital and the major economic-hub of the country; it lags behind in the ratio between healthcare workers compared to other neighboring countries, thus hampering proper, and timely healthcare. So, practice of self-medication is almost inevitable as the country has only 6 doctors, nurses, and midwives for every 10,000 populations, according to the report of health bulletin published yearly by the health ministry. ${ }^{6}$ Some studies on general tendency and pattern of self-medication practice of prescription-only drugs among students and people with or without medical knowledge showed alarming scenario in Dhaka city. ${ }^{7}$

The outbreak of coronavirus disease 2019 is putting a massive strain on vulnerable healthcare system in low and middle-income countries like Bangladesh. Inequitable access to healthcare is further widened by the socio-economic gap and sense of insecurity during this pandemic since the beginning of $2020 .^{8}$ Besides, the population of higher socio-economic standings are more potential to have access to better health information, medications and affordability that may lead to selfmedication practice in mass. Similarly, people with higher education are reported to have much distress, probably due to high self-awareness and access to mass information network. ${ }^{9}$

The combat against COVID-19 is still continuing in Bangladesh, with the highest incidence rate in Dhaka city. The available data by WHO revealed that the highest AR was observed to continue in the Dhaka (2321.7/1,000,000) and was highest $(9422.1 / 1,000,000)$ during April to June $2020 .{ }^{10}$ As there is no approved cure for COVID-19 or a vaccine against SARS-CoV-2, the aim of treatment is focused to manage and reduce symptoms until clinical recovery. Most people (around $80 \%$ ) are asymptomatic or mild infection that can be treated at home. In this case, one should be self-isolated for at least two weeks until recovered. Almost one in every five people infected with COVID-19 will require hospital support. Around 15\% of cases suffering severe infection require oxygen supplement for respiratory symptoms and $5 \%$ experience critical infections, requiring ventilation. Patients at a higher risk of severe or critical infections include older people, comorbid with underlying health conditions.

As stated in the National Guideline on case management of COVID-19 in Bangladesh, there is no precise effective treatment for COVID-19, the mainstay of management is early diagnosis and supportive care of symptoms and optimum support for organ function in severe illness. No drug is yet recommended as chemoprophylaxis as there is no quality evidence of efficacy and safety in COVID-19. Though patients should be managed in hospital setting; however, proper home care may also be advised with mild illness unless rapid deterioration or inability to avail hospital if necessary. ${ }^{11}$ But lack of rapid response, scarcity of hospital beds, absence of private practice, inadequate capacity of testing (RT-PCR), spread of unauthenticated treatment protocols are putting the citizens in dilemma of choosing medical advices. Lot of prescription-only drugs like antimicrobials (azithromycin, doxycycline), anti-parasitic (ivermectin), anti-malarial (hydroxychloroquine) along with leukotrienes inhibitor (montelukast), vitamin D, zinc, calcium and paracetamol are reported to become shortage in the dispensary and peripheral supply chain throughout the city. Because of commonly occurring symptoms of soreness or pain in throat, dry cough, fever, body ache, breathlessness; people started to take medicines without being diagnosed or tested for COVID-19. Besides the risk of misuse or overuse of these drugs may lead to immediate or delayed complications including adverse drug reactions (hypersensitivity, anaphylaxis), drug interactions, malfunction or destruction of vital organs such as liver, kidney; the practice of self-medication gives a deceitful sense of security and masking the correct diagnosis. Many countries are using different drugs but they are not using those as the guidelines and should only be used under the supervision of physicians on a case-by-case basis, not as a general recommendation. ${ }^{12}$

In view of this high prevalence of self-medication of prescription-only drugs in Bangladesh and its associated adverse socio-economic impact on individual and the healthcare service system, supply chain at large. This study is therefore done to evaluate the awareness, pattern and attitude towards self-medication among the high socio-economic and educated citizens in Dhaka during the outbreak of COVID-19 without testing, diagnose and prescription.

\section{METHODS}

This cross-sectional online survey adopted a descriptive non-experimental research design to investigate the awareness and practice of self-medication conducted from April to June 2020, the period during the nationwide lockdown and up surging of number of positive COVID19 cases. Because it was not feasible to do a communitybased sampling survey during this outbreak period, we decided to collect data online by convenience sampling. 
Using and relying on the authors' network with people living in Dhaka city, a structured questionnaire was circulated to complete via clicking the link, connected to Google form. The questionnaire contained brief introduction on the background, objective, procedure, voluntary nature of participation, declaration of anonymity and confidentiality, and notes for filling in the online questionnaire.

The inclusion criteria were set as, the adult citizens living in Dhaka city, aged 25 years or more, with education level of graduation or above, non-medical professionals, having email address, agreed to participate voluntarily. Respondents having involvement or knowledge on medical background (medical graduates, medical practitioners, nurses, medical researchers) were excluded to find out the public perceptions and their responses to take medications without prescription during COVID-19 outbreak. The frequencies of response were recorded in datasheet and observed according to demographic characteristics, sources of information, clinical symptoms and status of COVID-19 test results.

The questionnaire was developed and validated through face and content validity techniques. The face validity was achieved by giving the draft questionnaire to a few of the citizens with inclusion criteria at Dhaka city, to assess whether the response looks meaningful, well designed and/or a good measure of the construct to an innocent bystander. Information gathered from this exercise was used to refine and modify the questionnaire further. The content validity was done by giving the resultant questionnaire to two independent scholars from the fields of public health, pharmacology and social statistics to assess its appropriateness, clarity, coverage and relevance to the study. The incorporated draft questionnaire was recast for ambiguity and repetitive questions were struck off.

The reliability of the validated questionnaire was ascertained by test retest method. The questionnaire was administered twice at two weeks' interval on ten respondents from Dhaka city who practiced selfmedication during COVID-19 outbreak. The responses were compared and the reliability coefficient determined $(\mathrm{r}=0.83)$.

\section{RESULTS}

Total 639 participants completed the online survey questionnaire and submitted with e-mail verification. After excluding 13 respondents, of whom 10 were doctors by profession and 3 were below the minimum age limit (25 years); the final sample consisted of 626 valid participants. Among the final sample, 316 (50.47\%) respondents were from the age group of 45-54 years, 346 $(55.27 \%)$ were women, $312(49.84 \%)$ held a bachelor degree and $230(36.74 \%)$ engaged in non-civil services. Other demographic characteristics are shown in (Table $1)$.
Table 1: Frequency distribution of respondents by their socio-demographic features.

\begin{tabular}{|lll|}
\hline Variables & Frequency & Percentage \\
\hline Gender & & \\
\hline Male & 282 & 45.04 \\
\hline Female & 346 & 55.27 \\
\hline Age in years & & \\
\hline $25-34$ & 96 & 15.33 \\
\hline $35-44$ & 156 & 24.92 \\
\hline $45-54$ & 316 & 50.47 \\
\hline $55+$ & 58 & 9.26 \\
\hline Education level & & \\
\hline Undergraduate & 110 & 17.57 \\
\hline Bachelor degree & 312 & 49.84 \\
\hline Master degree & 178 & 28.43 \\
\hline $\begin{array}{l}\text { Doctoral and } \\
\text { advanced }\end{array}$ & 26 & 4.15 \\
\hline Work status & & \\
\hline Students & 84 & 13.41 \\
\hline Civil service & 13 & 2.06 \\
\hline Non-civil service & 230 & 36.74 \\
\hline $\begin{array}{l}\text { Self- } \\
\text { employed/business }\end{array}$ & 184 & 29.39 \\
\hline Retired & 38 & 6.07 \\
\hline Unemployed & 77 & 12.30 \\
\hline & & \\
\hline
\end{tabular}

Out of 626 respondents, only $73(11.66 \%)$ did not take any medication during the survey period as $12(1.91 \%)$ were negative by rRT-PCR test for COVID-19 and 61 $(9.74 \%)$ did not test. Remaining 132 respondents (21.08\%) was found positive test result for COVID-19.

The most frequently used prescription-only drug among the respondents were ivermectin $(77.15 \%)$, azithromycin $(54.15 \%)$, montelukast $(43.13 \%)$, calcium supplements $(41.37 \%)$, doxycycline $(40.25 \%)$ and hydroxychloroquine $(20.44 \%)$ respectively. The frequency of taking the prescription-only drugs among the respondents who were not even the diagnosed by rRT-PCR positive result, were reported higher with ivermectin $(76.68 \%)$ and azithromycin $(50.0 \%)$ as shown in Table 2.

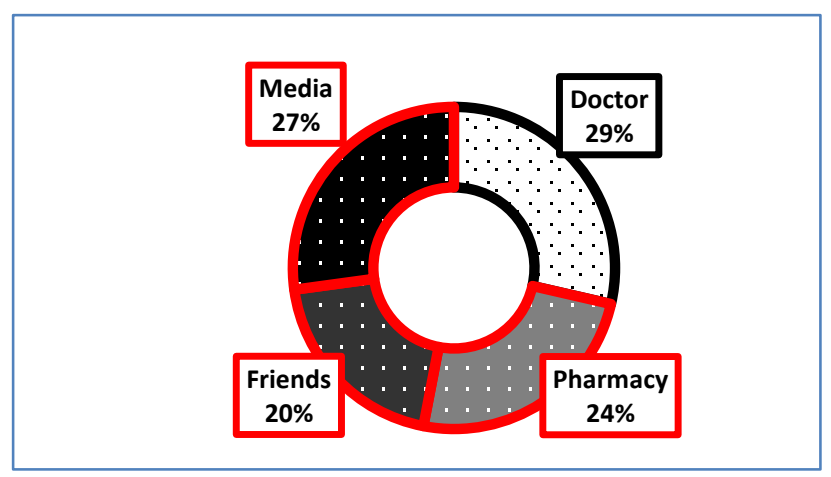

Figure 1: Distribution of respondents taken medication according to source of advices. 
Table 2: Frequency distribution of respondents by use of prescription only drugs.

\begin{tabular}{|c|c|c|c|c|c|c|c|c|c|c|c|}
\hline \multicolumn{2}{|c|}{ Variables } & 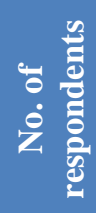 & 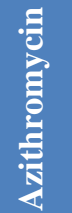 & 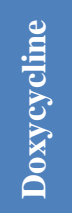 & 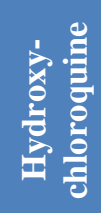 & 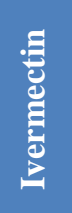 & 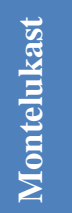 & 言 & 館 & $\stackrel{ }{\stackrel{D}{\circ}}$ & 乙 \\
\hline \multirow{3}{*}{$\begin{array}{l}\text { RT- } \\
\text { PCR } \\
\text { test }\end{array}$} & Positive & 132 & 111 & 93 & 84 & 109 & 62 & 103 & 81 & 44 & 0 \\
\hline & Negative & 78 & 20 & 31 & 0 & 55 & 10 & 21 & 69 & 41 & 12 \\
\hline & Not done & 416 & 208 & 128 & 44 & 319 & 198 & 0 & 109 & 0 & 61 \\
\hline \multicolumn{2}{|l|}{ Total } & 626 & 339 & 252 & 128 & 483 & 270 & 124 & 259 & 85 & 73 \\
\hline
\end{tabular}

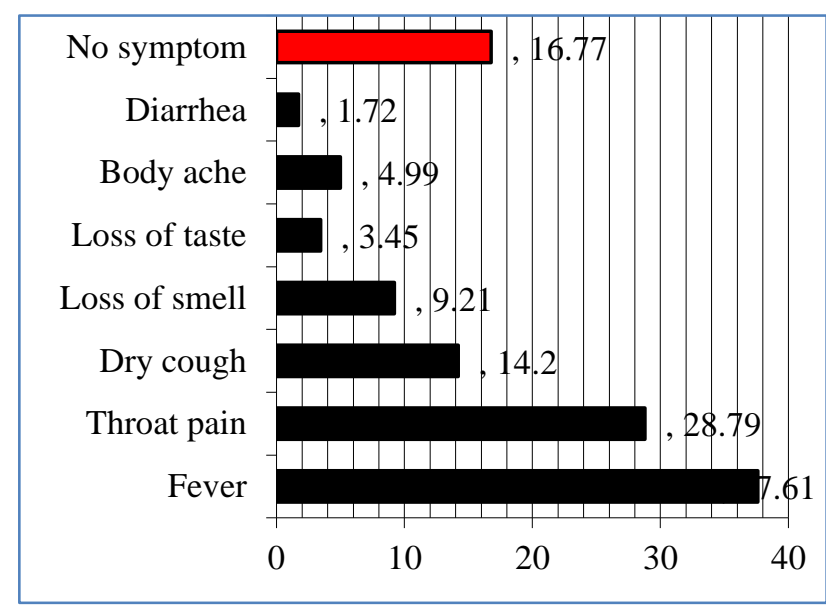

Figure 2: Distribution of respondents taken medication according to symptoms.

Among the respondents, only 179 (28.59\%) took medication with doctors' advice and remaining 447 $(71.40 \%)$ respondents took the drugs as "self-medication" by other sources like friends/family, pharmacy/dispensary and media/internet as shown in (Figure 1).

Total $105(16.77 \%)$ respondents took medications without having any symptoms. Among the remaining 521 respondents, common symptoms for which the respondents took medications were fever $(37.61 \%)$, throat pain $(28.79 \%)$, dry-cough $(14.20 \%)$, loss of smell $(9.21 \%)$, loss of taste $(3.45 \%)$, body ache $(4.99 \%)$ and rarely diarrhea $(1.72 \%)$ respectively as shown in (Figure 2).

\section{DISCUSSION}

To the best of our knowledge, this is the first online survey in Dhaka city evaluating the pattern and frequency of self-medication practice of prescription-only drugs in COVID-19 outbreak (April to June 2020) in Bangladesh. As the survey population was well-educated adults from different working status, the respondents' participation was expected to represent the sincerest and accurate scenario of the defined survey population.
Almost similar proportion of male and female participated in the study and most of them (50.47\%) belonged to the age group of 45-54 years. Highest number of respondents $(49.84 \%)$ were graduates (Bachelor degree) and lowest with doctoral degree $(4.15 \%)$. Only $2.06 \%$ respondents were from civil service and most of the rest were from non-civil service $(36.74 \%)$, self-employed or business $(29.39 \%)$ living in Dhaka city at the time of COVID-19 pandemic.

Among 626 survey population in Dhaka city who had taken medication for COVID-19, only $132(21.08 \%)$ were documented as positive and $78(12.45 \%)$ as negative by RT-PCR test. The rest of $416(66.45 \%)$ had never done the test, but almost $355(85.33 \%)$ had taken medication without doing any test for COVID-19. This finding could be due to having additional distress due to high self-awareness of their health as reported by Roberts et al among people with higher educational status. ${ }^{9}$ Having self-medication without detecting COVID-19 among a large number of respondents could also be due to feeling of insecurity influenced by availability of local medical resources, efficiency of public health system, and prevention and control measures taken in pandemic situation. ${ }^{17}$

The rate of self-medication of antimicrobial agents like azithromycin (54.15\%), doxycycline (40.25\%) were found much higher during the outbreak of COVID-19 comparing to $21 \%$ and $25 \%$ for azithromycin and doxycycline before the pandemic as reported by Chowdhury et al. ${ }^{13}$ Azithromycin was the fifth highest percentage of people with self-medication throughout the previous years, whereas it became most common antibiotic during the present pandemic. On the other hand, ivermectin being the anti-parasitic agent was selfmedicated by $77.15 \%$ of the respondents. This might be due to the nationwide broadcast of an experience by a team of Bangladeshi physicians and Bangladesh Medical College Hospital (BMCH) claimed as "outstanding results" in 60 patients with COVID-19 patients all of whom recovered in combination of ivermectin and doxycycline. ${ }^{12}$ This attempt was made on the outcome of an in-vitro study reported as a single treatment by ivermectin is capable of $\sim 5000$ folds reduction of viral 
load at 48 hours in cell culture. ${ }^{14}$ Self-medication of this drug was found highest (483/626) among the respondents irrespective of test results by RT-PCR. Though the drugs like chloroquine, hydroxychloroquine and azithromycin, was recommended in the treatment protocol of COVID19 patients in Bangladesh, according to the "National Guidelines on Clinical Management of Coronavirus Disease 2019" published in the health directorate's website; hydroxychloroquine was used much less $(20.44 \%)$ than any other antimicrobials without prescription. ${ }^{11}$ This could be due to mass publicity and sharing of news in national and international news and social media as the drug can cause hazardous abnormalities in cardiac rhythm in COVID-19 patients, and should be limited only in clinical trials or hospitals with adequate facilities to monitor any cardiac complications, warned by FDA in a safety communication briefing globally. ${ }^{12}$ The overall the prevalence and dominance of self- medication of antimicrobials in low and middle income countries were reported around $39 \%$ in previous studies before COVID19 pandemic; but was outrageously higher $(88.33 \%)$ in Dhaka city during the pandemic. ${ }^{15,16}$

Considering the sources or advice for medication, only $179(28.59 \%)$ respondents followed or consulted with doctors and rest by media or internet $(27.15 \%)$, pharmacy or dispensary $(24.44 \%)$ and friends or family $(19.8 \%)$. This finding was very much similar to the previous studies that reported the high prevalence of selfmedication (including antimicrobials) since people could obtain any drugs from the pharmacies without prescription even in the distant areas of the country. ${ }^{18}$ Moreover, during pandemic, people struggle to cope with constant news of the spread and effects of COVID-19 on news-media, social-media, internet without having adequate forms of social support and access to doctors as a result of lockdowns and self-isolation. ${ }^{8,19}$ Most of the respondents $(37.61 \%)$ took antibiotic as self-medication for fever during COVID-19 outbreak, followed by throat pain $(28.79 \%)$, dry cough $(14.20 \%)$; whereas almost $16.77 \%$ respondents had no symptoms whatsoever. Having inappropriate antimicrobials and supplementary medications (zinc, calcium, vitamin-D) without prescription is associated with the risk of drug interactions, masking symptoms of underlying diseases and most importantly, the development of anti-microbial resistance. ${ }^{20,21}$

Although there is no approved specific medication to prevent or treat COVID-19, this online survey among the educated adults with high socio-economic standings revealed that high prevalence of self-medication of prescription only drugs was persistent during the outbreak in Dhaka city. Unsolicited news of spread, effects and remedies in media channels, internet; mental stress of lockdown and isolation, insecurity and panic about scarcity of drug and healthcare support might have triggered up the practice self-medication. Psychological distress levels were also influenced by availability of local medical resources, prevention and control measures. ${ }^{22}$ There is sufficient evidence of increasing resistance to antibiotics in the Bangladesh resulting from irrational and misuse of antibiotics, where sales of antibiotics are not restricted at any level. ${ }^{23}$ Unopposed access to buy antibiotics and its injudicious use might provoke a longterm burden of drug-resistant strains with problems of under and over-dosage, treatment failure and severe adverse effects to vital organs. It also results in delay in care seeking, which results in paradoxical economic loss due to delayed diagnosis and irrational treatment. ${ }^{24}$ Bangladesh is already in the burden of lower ratio of healthcare workers and supply support system, with high rate of community-transmission of COVID-19 and require effective and efficient enforcement of regulation against free display and sales of drugs without prescription and individuals duly authorized. Immediate acceleration of health education campaigns, strict legislations on dispensing drugs and increasing the quality and access to healthcare are the important interventions that might change the people's health seeking behavior. ${ }^{25}$

\section{CONCLUSION}

The pattern of medication, including self-medication is an important health indicator, which reflect the degree of supply utilization and regulatory enforcement of healthcare services within a community. Pandemic situation of COVID-19 is likely to sustain for years and will have huge socio-economic and psycho-social impact on people's lifestyle and behavior, as predicted by the WHO and epidemiologists from different regions. Therefore, a vast nationwide survey and surveillance should be done on self-medication of mass population to protect them from the potential risks, overuse shortage and irrational financial involvement during the COVID19 outbreak.

\section{ACKNOWLEDGEMENTS}

We gratefully acknowledge all the respondents for their spontaneous participation in the study. We also extend our gratitude and thanks to Dr. Rawshan Ara Perveen for logistic and software support.

Funding: No funding sources Conflict of interest: None declared

Ethical approval: The study was approved by the Institutional Ethics Committee

\section{REFERENCES}

1. Oyediran O, Ayandrian EO, Olatubi MI. Awareness of risk associated with self-medication among patients attending out-patient department of a tertiary hospital in south western Nigeria. Int $\mathbf{J}$ Africa Nursing Sci. 2019;10:110-5

2. WHO. Report of the WHO Expert Committee on National Drug Policies. Geneva, Ed: 1, 1995. Available at: https://apps.who.int/iris/handle/ 
10665/63068? locale-attribute=en $\&$ show $=$ full.

Accessed on 23 June 1995.

3. Hughes CM, McElnay JC, Fleming GF. Benefits and risks of self-medication. Drg Saf. 2001;24:1027-37.

4. Hussain S, Malik F, Hameed A, Riaz H. Exploring health seeking behavior, medicine use and selfmedication in rural and urban Pakistan. Southern Med Rev. 2008;3:32-4.

5. GHWA. Available at: https://www.who.int/ workforcealliance/countries/bgd/en. Accessed on 15 May 2016.

6. Report in Dhaka Tribune. Available at: https://www.dhakatribune.com/health/2019/07/21/pat ient-doctors-nurses-ratio-bangladesh-lags-far-behind -its-neighbours. Accessed on 21 July 2019.

7. Nasir M, Zahan T, Parvin RA. Comparative study on knowledge, attitude and practice of self-medication among the medical and non-medical undergraduate students in Dhaka city. World J Pharmaceuticals Life Sci. 2017;3(4):17-20.

8. Kretchy IA, Danso AM, Kretchy JP. Medication management and adherence during the COVID-19 pandemic: Perspectives and experiences from lowand middle-income countries. Research Social Administrative Pharmacy. Available at: https://www.sciencedirect.com/science/article/pii/S15 51741120303326 (IN PRESS).

9. Roberts T, Esponda MG, Krupchanka D. Factors associated with health service utilizationfor common mental disorders: a systematic review. BMC Psychiatry. 2018;18:262.

10. WHO. Available at: https://www.who.int/docs/ default-source/searo/bangladesh/covid-19-whobangladesh-situation-reports/who-covid-19-update18-20200629.pdf?sfvrsn=6ef8ba08_2. Accessed on 4 August 2020.

11. National Guidelines on Clinical Management of Coronavirus Disease 2019 (COVID-19), by Disease Control Division, Directorate General of Health Services Ministry of Health and Family Welfare; Government of the People's Republic of Bangladesh Version-4. Available at: https://dghs.gov. bd/index.php/en/home/5343-covid-19-update. Accessed on 30 March 2020.

12. News Report. Available at: https://thelogicalindian. com/story-feed/awareness/selfmedication-coronavirus- covid-19-pandemic-20327. Accessed on 30 March 2020.

13. Chowdhury N, Islam MR, Hasan MM. Cephalosporin-3G, Highly Prescribed Antibiotic to Outpatients in Rajshahi, Bangladesh: Prescription Errors, Carelessness, Irrational Uses are the Triggering Causes of Antibiotic Resistance. Int J Pharmacy Teaching Practices. 2013;4(1):504-10.

14. Caly L, Druce JD, Catton MG. The FDA approved drug ivermectin inhibits the replication of SARSCoV-2 invitro. Antiviral Res. 2020;178:104787.
15. Ocan M, Obuku EA, Bwanga F. Household antimicrobial self-medication: a systematic review and meta-analysis of the burden, risk factors and outcomes in developing countries. BMC Public Health. 2015;15:742.

16. Morgan DJ, Okeke IN, Laxminarayan R. Nonprescription anti-microbial use worldwide: a systematic review. Lancet Infect Dis. 2011;11:692701.

17. Wind TR, Komproe IH. The mechanism that associate community social capital with post-disaster mental health: a multilevel model. Soc Sci Med. 2012;75:1715-20.

18. Islam MS. Self-medications among higher educated population in Bangladesh: an email-based exploratory study. Internet J Health. 2007;5:2.

19. Huibo L, Zheng S, Liu F. Fighting against COVID19: Innovative strategies for clinical pharmacists. Res Soc Adm Pharm 2020; (IN PRESS). Available at: https://www.sciencedirect.com/science/article/pii/S15 51741120303284.

20. Okeke IN, Klugman KP, Bhutta ZA. Anti-microbial resistance in developing countries Part II: strategies for containment. Lancet Infect Dis. 2005;5:568-80.

21. World Health Organization. Community-Based Surveillance of Antimicrobial use and Resistance in Resource constrained settings. A report on five pilot projects. Geneva, Switzerland: WHO; 2009. Available at: http//www.apps.who.int/medicinedocs /documents/s16168e.pdf. Accessed on 4 August 2020.

22. Qiu J, Shen B, Zhao M. A Nationwide survey of psychological distress among Chinese people in the COVID-19 epidemic: implications and policy recommendations. General Psychiatry. 2020;33:e100213.

23. Biswas M, Roy MN, Manik IN. Self-medicated antibiotics in Bangladesh: a cross sectional health survey conducted in the Rajshahi city. BMC Public Health. 2014;14:847.

24. Kalyan VS, Sudhakar K, Srinivas P. Evaluation of self-medication practices among undergraduate dental students of tertiary care teaching dental hospital in south India. J Education Ethics Dentistry. 2013;3(1):21-5.

25. Alghanim SA. Self-medication practice among patients in a public health care system. Eastern Mediterranean Health J. 2011;7(5):409-16.

Cite this article as: Nasir M, Chowdhury ASMS, Zahan T. Self-medication during COVID-19 outbreak: a cross sectional online survey in Dhaka city. Int J Basic Clin Pharmacol 2020;9:1325-30. 